\title{
DOAÇÃO E CUIDADO: RELATOS DE MÃES QUE SE DEDICAM INTEGRALMENTE AO CUIDADO DE FILHOS COM DEFICIÊNCIA
}

\author{
DONATION AND CARE: REPORTS OF MOTHERS WHO IF INTEGRALLY \\ DEDICATED TO CARING FOR DISABLED SONS
}

\author{
Thallya Leite Miguel ${ }^{1}$ \\ Ruty Vanessa Bernardo Silvino ${ }^{2}$ \\ Julianne Milenna Padilha Rolim ${ }^{3}$
}

\begin{abstract}
RESUMO: O estudo teve como objetivo apontar quais os processos psicológicos envolvidos na dedicação integral e no cuidado de filhos com deficiência. Participaram da pesquisa oito mães de pessoas com deficiência atendidas no CER IV - Centro Especializado em Reabilitação Mens Sana. Os dados foram obtidos através de entrevistas semiestruturadas, realizadas individualmente, e posteriormente analisadas de acordo com a análise de conteúdo. Os resultados apontam que para entender a realidade do cotidiano do cuidado de filhos com deficiência é preciso entender as subjetividades das mães, as realidades em que vivem. A maternidade traz consigo uma realidade cercada de dores e prazeres, tais prazeres servem como motivação para a continuação do cuidado constante e integral, pois mesmo que não esteja presente fisicamente, a mãe está presente simbolicamente, pois mesmo distante do filho está sempre pensando e comandando seus cuidados. Conclui-se que a partir de uma compreensão de uma maternidade como algo particular, com significantes singulares e uma experiência de doação e cuidado, dores e amores, espera-se que tanto as mães, como as pessoas em geral passem a entender que as fragilidades, o cansaço e a culpa também fazem parte do processo e isso não minimiza o amor entre mãe e filho.
\end{abstract}

Palavras-chave: Maternidade. Cuidado. Deficiência.

ABSTRACT: The study aimed to point out which psychological processes are involved in the integral dedication and care of children with disabilities. Eight mothers of people with disabilities attended the CER IV - Mens Sana Specialized Rehabilitation Center. The data were subjected to semi-structured interviews, conducted and subsequently analyzed according to a content analysis. The results point to understand the reality of daily child care with the impact it is necessary to understand as subjectivities of mothers, as realities

\footnotetext{
Discente do curso de Psicologia da Autarquia de Ensino Superior de Arcoverde - Email: Thallyaleitero@gmail.com

2 Discente do curso de Psicologia da Autarquia de Ensino Superior de Arcoverde - Email: Rutyrita@hotmail.com

3 Psicóloga, Especialista em Psicologia Organizacional, Especialista em Avaliação Psicológica, Especialista em Psicologia do Trânsito. Mestranda em Gestão Empresarial. Docente do curso de Psicologia da AESA/ESSA e Faculdade Integrada CETE/FIC Garanhuns. E-mail: juliannepadilha@gmail.com.
} 
in which they live. Motherhood brings with it a reality surrounded by pains and pleasures, such benefits as motivation for the continuation of constant and integral care, because even if not physically present, the mother is symbolically present, because even away from the child, she is always thinking and commanding her own. care. It is concluded that from an understanding of motherhood as something specific, with singular signifiers and an experience of treatment and care, pains and loves, it is expected as much as mothers, as people in general, understand that the weaknesses Tiredness and guilt are also part of the process and this does not minimize the love between mother and child.

Keywords: Maternity. Watch out. Deficiency.

\section{INTRODUÇÃO}

O termo deficiência significa toda e qualquer perturbação ou limitação de estrutura anatômica ou de uma função, a qual pode ser de ordem fisiológica ou psicológica, podendo causar o impedimento dos movimentos, das sensações, da cognição e do intelecto, resultando assim em limitações substanciais em suas atividades cotidianas (REY, 2003). É importante ressaltar que a definição de deficiência é complexa, pois contempla um envolvimento de diversos elementos e aspectos históricos, culturais e sociais, pois não é possível falar de maneira abstrata e generalista, visto que pessoas com deficiência não possuem um determinado padrão e, portanto, deve ser individual o tratamento de cada sujeito. (NOGUEIRA et al., 2016)

Segundo Tomaz et al (2017), seus efeitos vão para além das questões da saúde física e mental, gerando uma grande mudança na vida dos familiares e da sociedade com quem convive. Para que o indivíduo tenha qualidade de vida é preciso uma adaptação das pessoas que o cercam e de políticas públicas que o incluam de forma que preserve os direitos essenciais de qualquer ser humano.

Diante da circunstância de ter uma deficiência se faz necessário o auxílio de uma pessoa, para que o mesmo possa realizar suas atividades cotidianas, tal função consequentemente é passada para um familiar, o qual passa por um processo de reconfiguração para que possa se dedicar inteiramente ao papel de cuidador. E é neste contexto que surge a mãe, que vivencia uma nova experiência frente as exigências de ter um filho com deficiência. (OLIVEIRA et al., 2016)

Segundo Martins et al (2014) os genitores ainda mantem o modelo tradicional, no qual a mãe assume a função principal de cuidadora e de absoluta disponibilidade e o pai 
assume a função de mantenedor e de auxílio, com relativa ausência ao cuidado do filho. $O$ autor coloca que a diferenciação de papéis de gênero apresentada entre pais e mães, que a literatura traz como tradicionalista, não trata-se apenas de um fenômeno comportamental, mas de um fenômeno que abrange valores e ideologias que permeiam os papéis masculinos e femininos, ou seja, paternos e maternos.

Segundo Malta et al (2016) a taxa de prevalência de deficiência no Brasilé de 6,2\% o que resulta em aproximadamente 12,4 milhões de pessoas que possuem algum tipo de deficiência auditiva, física, intelectual ou visual. Estes números evidenciam a relevância de estudos acerca desta temática, pois retrata a realidade da vida de um alto percentual de pessoas portadoras de deficiência, para tanto também é indispensável contextualizar as condições psicológicas dos familiares que participam ativamente da rotina dos mesmos.

Dessa forma, esta pesquisa visou apontar quais os processos psicológicos envolvidos na dedicação integral e cuidado de filhos com deficiência, apontando os tipos de deficiência dos filhos das entrevistadas, apresentando as vivências emocionais das mães que possuem filhos com deficiência, caracterizando o filho "perfeito" sobre a ótica psicanalítica a partir dos relatos das mães entrevistadas e compreender enfim, as motivações que levam as mães ao cuidado integral dos filhos com deficiência.

\section{MÉTODO}

Foi realizada uma pesquisa de cunho qualitativo, a fim de compreender os processos psicológicos envolvidos no cotidiano de dedicação integral e cuidado de filhos com deficiência, baseado em uma perspectiva psicanalítica. De acordo com Minayo (2006) a pesquisa qualitativa é capaz de analisar dados que não podem ser mensurados numericamente, voltando-se aos aspectos qualitativos do objeto a ser estudado, ou seja, visa compreender a lógica interna de grupos e instituições, os valores culturais e representações sobre sua história e temas específicos, as relações entre indivíduos e movimentos sociais ligados aos processos históricos, sociais e de implementação das políticas públicas na sociedade.

Sendo assim, foram entrevistadas oito mães de pessoas com deficiência, por meio de entrevista semiestruturada com pergunta disparadora. Segundo Marconi e Lakatos 
(2003, p. 197), na entrevista semiestruturada “o entrevistador tem liberdade para desenvolver cada situação em qualquer direção que considere adequada. É uma forma de poder explorar mais amplamente uma questão”.

A pesquisa será analisada de acordo com os preceitos da análise de conteúdo. Bardin (1977), reflete que essa forma de conteúdo é um conjunto de técnicas de análise das comunicações, "visando a obter, por procedimentos sistemáticos e objetivos de descrição do conteúdo das mensagens, indicadores que permitam a inferência de conhecimentos relativos às condições de produção/recepção destas mensagens” (Bardin, 1977, p. 42).

A pesquisa aconteceu no CER IV - Centro Especializado em Reabilitação Mens Sana, que fica localizado na Rua Ubirajara Ribeiro Mindêlo Filho, $n^{\circ} 77$, no bairro São Miguel, na cidade de Arcoverde-PE.

A relevância de pesquisas com o método psicanalítico é corroborada na afirmação de que através da mesma é possível alcançar a vitalidade da escuta e da postura investigativa psicanalítica (SILVA; MACEDO, 2016).

\section{RESULTADOS E DISCUSSÃO}

Esta pesquisa teve como público alvo oito mulheres, que por questões éticas tiveram seus nomes substituídos e estão relacionados abaixo por idade, cor, renda, número de filhos, tipo de deficiências dos filhos e se possuem ou não vínculo empregatício.

Tabela I - Dados da amostra

\begin{tabular}{|c|c|c|c|c|c|c|}
\hline Nome & Idade & Cor & $\begin{array}{l}\text { Renda Mensal / } \\
\text { Benefício }\end{array}$ & $\begin{array}{l}\text { № de } \\
\text { filhos }\end{array}$ & $\begin{array}{l}\text { Tipo de deficiência dos } \\
\text { filhos }\end{array}$ & $\begin{array}{l}\text { Possui vínculo } \\
\text { empregatício }\end{array}$ \\
\hline $\begin{array}{l}\text { Mãe } \\
\text { Esperança }\end{array}$ & 29 & Parda & $\begin{array}{l}\mathrm{R} \$ 400,00 \\
\text { Classe E }\end{array}$ & 2 & $\begin{array}{lr}\text { Transtorno de } & \text { conduta } \\
\text { não-socializado } & \text { e } \\
\text { Autismo } & \\
\end{array}$ & Não \\
\hline Mãe Solidão & 42 & Parda & $\begin{array}{l}\mathrm{R} \$ 7.000,00 \\
\text { Classe C }\end{array}$ & 2 & $\begin{array}{l}\text { Transtorno } \quad \text { Mental } \\
\text { Moderado }\end{array}$ & Sim \\
\hline $\begin{array}{l}\text { Mãe } \\
\text { Realização }\end{array}$ & 43 & Parda & $\begin{array}{l}\text { R\$ r.8oo,oo } \\
\text { Classe D } \\
\end{array}$ & 2 & Retardo Mental Leve & Sim \\
\hline $\begin{array}{l}\text { Mãe } \\
\text { Normalidade }\end{array}$ & 32 & Morena & $\begin{array}{l}\mathrm{R} \$ 700,00 \\
\text { (Classe E }\end{array}$ & I & TDAH & Sim \\
\hline Mãe Cuidado & 48 & Parda & $\begin{array}{l}\mathrm{R} \$ 2.500,00 \\
\text { Classe C }\end{array}$ & 6 & Ataxia Cerebelar & Não \\
\hline $\begin{array}{l}\text { Mãe } \\
\text { Aprendizado }\end{array}$ & $3 \mathrm{I}$ & Negra & $\begin{array}{l}\mathrm{R} \$ 3.000,00 \\
\text { Classe C }\end{array}$ & I & Autismo & Não \\
\hline
\end{tabular}




\begin{tabular}{|c|c|c|c|c|c|c|}
\hline & & & $\begin{array}{l}\text { (Possui } \\
\text { benefício) }\end{array}$ & & & \\
\hline $\begin{array}{l}\text { Mãe } \\
\text { Gratidão }\end{array}$ & 33 & $\begin{array}{l}\text { Indígen } \\
\mathrm{a}\end{array}$ & $\begin{array}{l}\mathrm{R} \$ \mathrm{I} .996,00 \\
\text { (Possui } \\
\text { benefício) }\end{array}$ & 4 & $\begin{array}{l}\text { Possui filhos gêmeos com } \\
\text { Retardo Mental Grave e } \\
\text { Autismo }\end{array}$ & Não \\
\hline Mãe Culpa & 56 & Morena & $\begin{array}{l}\text { R\$ 998,oo } \\
\text { (Possui } \\
\text { benefício) }\end{array}$ & 5 & Convulsão & Não \\
\hline
\end{tabular}

Fonte: Pesquisa de campo realizada entre os meses setembro a outubro de 2019.

Observações: As informações são descrições exatas dos relatos das mulheres entrevistadas. Para substituir os nomes verdadeiros das mulheres, foram utilizados nomes de sentimentos citados por elas, tais nomenclaturas não representam a totalidade de atributos que possam envolver suas experiências, o critério para a utilização foi a ênfase e repetição em seus discursos. A classificação por classes econômicas foram retiradas do site oficial da FGV SOCIAL, Centro de políticas sociais.

\section{A "normalidade" como foco do cuidado}

Nessa categoria, acoplamos relatos que destacam o termo "normalidade" trazido pelas mães ou que subjetivamente surgem na fala das participantes como um gatilho disparador de foco de cuidado. Para tal categoria, iniciamos nossa discussão a partir das pontuações de Zanello (2018) quando assinala que o cuidado foi historicamente atribuído a grupos subalternos de sujeitos, desses grupos, destacam-se as mulheres pobres e negras que "naturalmente" se encontravam disponíveis a servidão e a disponibilidade do cuidado.

Por vezes, as mães acabam superprotegendo os filhos e oferecendo mais cuidados do que o normal, isso ocorre numa tentativa de conter as limitações dos seus filhos, o que acaba gerando uma maior dependência destes cuidados maternos e também pode estar relacionado a uma tentativa de reparação de danos. Desse modo, as mães maximizam a deficiência na medida que diminuem ou provém a autonomia dos seus filhos (OLIVEIRA; POLETTO, 2015).

A culpa é o sintoma que o dispositivo materno impera na sociedade, trazendo a culpabilização da mãe por não ser "boa o suficiente", estando ela em todo lugar, e nesse 
caso, apontada na hipótese de que seu filho não nasceu "normal" por algum erro de ordem não natural. Dessa forma, destacamos os relatos a seguir:

\begin{abstract}
a gente que é mãe não é fácil, a gente que tem filho normal já não é fácil, porque eu tenho um filho adolescente que só Deus na causa, e quando você tem um especial? Não sei se vocês são mãe, mas eu sou, é muito dificultoso ser mãe, você ensina o filho a ir no caminho certo e o filho só quer ir pra onde você não quer, aí você tem essas dificuldades sendo mãe, aí já tem outra dificuldade de ter um filho especial, que às vezes até o mais velho cobra porque eu faço isso com ele. (Mãe Esperança).
\end{abstract}

Mas assim eu dou o máximo, o que eu posso fazer eu dou o máximo de mim pra que futuramente ele possa socializar com as pessoas como uma criança normal, ter uma vida normal, sabe!? (Mãe Esperança).

No início a culpa era nossa, porque a gente não estimulava, por conta de alguns problemas que tinham no relacionamento, então aquilo poderia ser resposta a esses problemas, e como a gente via isso? No tempo dela, ela vai começar a andar e essas diferenças vão passar ou não existir, diferenças de comportamento entre outras crianças ou serão mínimas e ainda tinha aquela questão do pai dizer assim: Eu também sou assim! Eu era assim! (Mãe Solidão).

A necessidade de presumir que a deficiência é um fato biológico e com atributos universais, precisaria ser problematizada epistemologicamente. Porém, é necessário inverter aquilo que foi arquitetado como normal e que se transformou em um problema habitual, através da compreensão do discurso da deficiência, para mostrar que o objeto desse discurso não é a pessoa com deficiência ou o indivíduo que não aprende de acordo com ritmo das outras pessoas, mas é a forma como sociedade espera que seja. (BIROLI, 2017)

É importante ressaltar que envolve outros fatores como os processos sociais, históricos, econômicos e culturais que regulam e controlam a forma de como são pensados e idealizados os sujeitos, a partir do ponto de vista dos outros. Ou seja, a deficiência não é apenas uma questão biológica, é muito mais complexa. Portanto, a deficiência não é um problema das pessoas com deficiência ou apenas dos seus familiares e dos especialistas que acompanham os seus tratamentos, pois está relacionada com a ideia da normalidade e com toda a sua historicidade (BIROLI, 2017).

\title{
Vivências emocionais: Gênero, solidão, culpa e religião.
}

Scavone (2004), salienta que historicamente de um ponto de vista social, ser mãe, dar a vida, está intimamente ligado ao cuidado da vida, e, portanto, esta ligação entre mães 
e filhos. Culturalmente é designada à mulher uma tradição somática feminina, que é aprendida ao longo da vida, muitas vezes transmitida de mãe para filha, de amiga para amiga, na qual elas aprendem sobre como se manifestam os sinais de saúde e doença nos seus próprios corpos e nos corpos de seus filhos, sendo atribuída à mãe os interesses e implicações da saúde dos filhos e consequentemente o cuidado nesses processos.

Baseada em uma concepção cultural moldada em um modelo patriarcal, a atribuição do cuidado dos filhos recai quase que inteiramente para as mães, em seu cotidiano essas mães estão envolvidas em diferentes tarefas que compreendem o cuidado e criação dos filhos, manutenção da casa e por vezes atrelado a um vínculo empregatício externo, portanto quer estejam criando os filhos sozinhas ou com um parceiro, para o modelo atual de maternidade exigente é como se as mulheres carregassem com elas uma preocupação permanente que exige atenção, paciência e disponibilidade. Tal responsabilidade se manifesta em suas vivências como um sentimento de solidão, no qual sentem que só elas tem o dever e responsabilidade no cuidado dos filhos. (DONATH, 2016) Tais vivências podem ser evidenciadas nos relatos a seguir:

Ah, e só é você?’ É um núcleo sou eu, L. e E., que é meu filho mais novo, meu marido trabalha muito, quem sustenta a casa é ele, então de uma certa forma ele se voltou totalmente pra isso. Se ele me dá apoio em relação à L.? Acho que ainda é aquela questão, eu mantenho a casa, você cuida dos filhos, vamos vivendo, tá beleza!

Se hoje tá sendo assim então vai permanecer assim, eu posso mudar meu comportamento, eu posso mudar o do outro? Não posso. Então enquanto eu estou conseguindo eu estou fazendo, eu estou tentando, eu ainda não desisti, mas não posso dizer o dia de amanhã, talvez amanhã eu acorde muito cansada e diga agora eu desisti, por mim L. não vai mais pra escola, por mim L. só fica em casa, pode ser que aconteça, mas por enquanto L. vai pra escola. (Mãe Solidão).

"É bem complicado pra mim, eu como mãe tem hora que a minha emoção tá lá embaixo, tem horas que eu tava no fundo do poço, mas tinha que voltar pra lutar pra acudir eles porque senão quem que ia correr atrás? O pai ajuda mas não é como a mãe, porque a mãe se preocupa mais, a personalidade dele é um pouco mais diferente né de uma mulher." (Mãe Gratidão).

É muito difícil né!? É difícil, porque na época eu estava sozinha com ele, eu tinha deixado o pai dele, fiquei sozinha. É muito difícil, a gente se pergunta por quê com a gente né!? Por quê acontece isso com a gente? Aí depois Deus vai orientando a gente e dá discernimento pra gente conseguir conciliar as coisas, trabalhar e cuidar, tratar, ter cuidado nele, é muito difícil, não é fácil não!” (Mãe Realização).

No começo assim, eu fiquei meia que..., acho que como todo mundo, meio perturbada assim, porque é complicado né!? Mas aí depois eu fui entendendo que 
ela depende muito de mim, em tudo ela depende muito de mim, então são ossos do ofício. (Mãe Cuidado).

Imbuída de tamanha responsabilidade, a mãe carrega o peso de ser uma "boa mãe", de dar conta sozinha de todas as demandas que surgirem no cotidiano do cuidado dos filhos, devido a uma dita expectativa social, situação agravada quando se trata do cuidado de um filho que possui deficiência, que demanda outros tipos de esforços por parte do cuidador. A consciência da maternidade está sempre presente, 24 horas por dia, 7 dias por semana, portanto mesmo ao se ausentar fisicamente para realização de outras tarefas, a mãe muitas das vezes carrega um sentimento de culpa por não estar no controle dos cuidados e ter que delegar para outra pessoa esses cuidados que atribui ser de sua responsabilidade (DONATH, 2016). Tal afirmação pode ser corroborada nos relatos a seguir:

[...] foi um tempo bem doido, porque L. estava precisando de acompanhamento, eu com um bebezinho e fazendo faculdade que era de manhã e de tarde, e eu trabalhava na hemodiálise, mudei meu horário de trabalho e comecei a trabalhar de noite, a escala de lá era puxada, como ainda é, então eu trabalhava 12 por 36, uma noite sim, uma noite não, e estudava. Nesse momento eu não era mãe, não vou mentir pra vocês, eu passei dois anos cuidando de mim, fazendo a minha faculdade e trabalhando.” Mãe Solidão

"...aí foi nesse período que a faculdade terminou que eu comecei a perceber que estava acontecendo com meus filhos, L. precisava de acompanhamento, e aí o meu “eu” morreu." (Mãe Solidão).

Mas é que nem eu tô dizendo, tem as dificuldades né!? Muita! Tem horas que você chora, tem horas que você se desespera por você perder o controle da situação, porque muitas vezes eu perco o controle da situação naquele momento que ele tá agressivo, que ele tá gritando, sabe!? Mas assim, às vezes eu deixo ele lá e começa a dar uma agonia no meu juízo, mas daqui a pouco passa, aí quando ele às vezes se reconhece né!? ele pede desculpa e promete que não vai fazer mais, mas faz de novo." (Mãe Esperança).

A culpa é um indício de que o dispositivo materno está desempenhando sua função e de que o modelo padrão foi introjetado. As mães sentem-se culpadas por vários motivos que podem variar desde não serem o que as julgam como "boas mães", como por exemplo abrirem mão de um projeto pessoal em função de seus filhos, até reconhecerem e aceitarem seus sentimentos como raiva e revolta quando os filhos fazem algo que não atende às suas vontades o que pode ser comum diante das vivências diárias. Por outro lado, quase não escutamos reprovação aos pais, mesmo aos que abandonam ou são ausentes. No caso da paternidade a culpa aparece por outro viés, a qual não está relacionada a paternidade 
propriamente dita, mas a capacidade de ser o mantenedor e o provedor principalmente da condição financeira da família (ZANELLO, 2018).

Dentre as vivências emocionais destacadas houve uma forte presença do fator religioso nos discursos das mães, elas encontram nesse contato com a espiritualidade explicações positivas ou negativas para a deficiência do filho, no sentido de serem agraciadas ou castigadas pela condição de seus filhos.

Mas eu me sinto escolhida por Deus né!?, ainda dizem que tem aquele ditado que "Deus dá o cobertor conforme o frio né?" e eu acredito muito nisso que algum aprendizado eu vou ter que levar pra minha vida. Um dia eu vou descobrir porque Deus me escolheu para ser mãe de gêmeos especiais. (Mãe Gratidão).

foi castigo de T. nascer assim" porque eu tive o aborto do outro até hoje eu digo que isso é castigo de T. ter nascido, porque eu tenho cinco, eu tenho quatro todos nasceu normal só T. que nasceu desse jeito, ai eu fico assim... (Mãe Culpa).

Você gerar...eu sempre falo assim que Deus é maravilhoso, porque Deus ele fez o ser humano tão perfeito que duas pessoas geram outra pessoa, que futuramente vai tá igual a gente, então assim é uma dificuldade, mas também é muito prazeroso, porque é uma benção que Deus dá a gente com todas as suas dificuldades, porque não é fácil ser mãe independente de ser especial ou não, não é fácil ser mãe. (Mãe Esperança).

Para além das explicações acerca das deficiências de seus filhos, a religião surgiu como grande fonte de força e conforto na vida dessas mães, espontaneamente em suas falas as mães trazem o papel das crenças espirituais em suas vidas, elas são responsáveis por sustentar suas ações, valores e comportamentos, são elas que estruturam e dão sentido a existência no mundo. Portanto ao mesmo tempo em que dá sentido a existência, as crenças dão suporte para essas mulheres acreditando de que há algo maior responsável por apoiar qualquer sofrimento por elas vivenciado, algo que transcende a experiência humana e pode dar resposta a todas as suas questões (CÂMARA, 2015).

Nas falas que seguem podemos notar afirmações em que se tornam evidentes a importância da religião no cotidiano de cuidado aos filhos com deficiência:

Mas ainda está fazendo tratamento psicológico?

Não, não, não eu só fui uma vez, mas eu digo isso é besteira, o que é que eu tô fazendo aqui, não, eu tenho que assim conquistar meu senhor e o meu senhor vai me orientar, ai comecei que eu sou evangélica né, a pastora disse você não tem nada, só coisa da sua cabeça sabe o que é que você faz bota teu joelho no chão e vai pedir socorro a Jesus, que Jesus vai te orientar, o que você vai fazer viu e foi dito e certo viu, graças a Deus que hoje eu sei lutar com T. (Mãe Culpa). 
E eu digo a ela L. por mais que você se sinta só, você nunca está sozinha, nós somos evangélicos, então eu quero também que ela cresça crendo em cristo, que com ele nós nunca estamos sozinhos e a questão de rejeição e de sermos tratados com indiferença e um certo preconceito independente do nosso grau intelectual, isso vai acontecer, mas nó precisamos estar cientes de que nós não estamos nunca sozinhos, tem sempre Deus cuidando da gente, eu digo a ela Deus tá sempre cuidando de você, nunca se sinta só. (Mãe Solidão).

Hoje raramente ele me agride, mas já me agrediu muito, ele "avuava" em cima de mim e perder o controle é quando você não sabe o que fazer naquele momento, não sabe como vai reagir sabe!? Como é que deve reagir nesse momento...é isso que eu tô falando, perder o controle da situação, tá entendendo? E é muitas das vezes que a gente começa a chorar, clamar a Deus né!? que Deus é misericordioso e uma hora aquilo ali vai passar sabe!? É a fé da pessoa, que uma hora vai passar, aí aquilo ali passa, nem que vai ter mais na frente, vai ter novamente, a gente sabe que isso é processo todos os dias, que não é fácil, mas é assim mesmo, a vida da gente. (Mãe Esperança).

A base que as mães que possuem filhos com deficiência procuram na religião serve como uma importante rede de apoio e conforto nos momentos de angústia, frustração e solidão, de forma que a religião e família são suporte para as vivências do presente e de conforto para as inseguranças do futuro incerto dos filhos, incertezas que incluem as condições reais e todos os seu desejos e expectativas para a vida deles, pois quando um filho não tem nenhum tipo de comprometimento é mais fácil imaginar como ele irá se desenvolver, sendo então o futuro do filho com deficiência uma grande incógnita, na qual ela busca resposta na religião (SMEHA; CEZAR, 20II).

\section{Padecer no paraíso: A idealização do filho perfeito}

Durante a gravidez a mulher passa por grandes mudanças, que podem ser psicológicas e fisiológicas. O nascimento de uma criança é um fato marcante na vida da família e dos pais, pois é neste momento que se inicia uma fase nova de transição, a qual modifica os papéis e as funções dos indivíduos na relação familiar, situação que se intensifica quando se trata do nascimento de um filho com deficiência (MARTINS et al., 2014).

Segundo Lebovici (1987), na mente materna existem três tipos de bebês ao mesmo tempo: um bebê edípico, um bebê imaginário e o bebê propriamente dito "o bebê real". O bebê edípico resulta da fantasia da mãe, através das revivências edípicas da infância da mãe enquanto ainda era criança. $O$ segundo bebê é o imaginário o qual é idealizado diante das 
expectativas construídas na imaginação dos seus progenitores como o filho perfeito. E por fim, o bebê propriamente dito o que ao nascer os pais seguraram no colo, ou seja, o bebê real que estava se desenvolvendo dentro do útero da mãe. O que pode ser observado nas falas seguintes:

É padecer no paraíso, ah, é a coisa melhor que tem né!? Coisa melhor eu acho que não existe não! É tudo, é experiência com os filhos, e a realização de sonhos que a gente quando casa quer ter filhos né!? (Mãe Realizada).

Independente da deficiência ser mãe é algo sublime é você gerar uma outra vida dentro de você, não sei explicar cada sentimento que vai crescendo dentro da gente a cada mês de gestação, até chegar no último e a gente fica mais ansiosa ainda porque quer ver se tá tudo direitinho, se tem todos os dedos, se é perfeito, que cor é o olho, que cor é cabelo, que cor vai ser a pele, independente de ter algum tipo de deficiência, ser mãe é algo que só quem consegue ser é que sabe explicar o sentido, porque eu costumo dizer que esse dom da maternidade não era pra ser dado pra qualquer mulher, porque nem toda mulher tá preparada pra ser mãe. (Mãe Aprendizado).

Achava que era só transtorno, mas aí aceitar que é difícil, ele tinha 5 anos, quando foi com 6 anos minha família ajeitou, aí eu fiz uma consulta particular com um Neuro, aí lá foi onde ela descobriu na hora, como eu já tinha todos os exames aí ela disse "Olhe mãe..." ela foi até dura "ele tem autismo, olhe mãe esse transtorno de conduta não-socializado é o autismo mãe, basta olhar no olho do seu filho" ela foi até um pouco dura, então né imagine, meu mundo caiu, eu não tinha noção do que era o autismo, que a gente sabe que não é só um grau, é vários graus, tem o grau mais grave, já tem outro que é mais leve, mas aí meu mundo desabou né!? Aí meu mundo desabou... (Mãe Esperança).

Diante do nascimento de uma criança, a primeira coisa que os seus progenitores fazem é conferir se o filho é "perfeito" e assim conseguem ficar aliviados e comemorem diante a concretização da idealização desse filho. Portanto, caso isso não aconteça como esperado, se dá a morte do filho idealizado e de todas as expectativas que foram construídas até o momento, sendo assim, a constatação de ter um filho com deficiência pode gerar diversos sentimentos nos pais, como negação, tristeza, ansiedade, culpa, incapacidade, estresse, medo e insegurança.

\section{Motivações sobre o cuidado integral}

Biroli (2017) afirma que uma das grandes críticas do feminismo quanto a maternidade é que ela tem sido historicamente definida pela divisão do trabalho, sobrecarregando às mulheres que abdicam da participação em outras esferas da vida para tomar o cuidado integral dos filhos e que mesmo quando possuem uma vinculação 
empregatícia estão totalmente envolvidas no cuidado. Portanto para significar o protagonismo do cuidado integral a mulher dispõe de alguns mecanismos motivacionais que servem como pulsão para lidar com as dificuldades do cotidiano.

Segundo Huertas (200I) a motivação é “o que constitui um componente energético do ser humano, o que move e direciona para algo que nem sempre é tangível nem evidente". A palavra motivação pretende explicar ou compreender a explicação de uma determinada ação de um sujeito. A explicação surge então como uma possível resposta a um questionamento, com a finalidade de explicar um determinado comportamento.

No entanto, os motivos capazes de definir uma ação não são somente os aspectos motivacionais. As atitudes das mães que se dedicam ao cuidado integral podem ser explicadas ou compreendidas através de outros fatores como os determinantes afetivos, cognitivos, e sociais, para além dos motivacionais. Isso acontece a partir de uma predisposição particular na qual as mães reagem de maneira pessoal sobre a influência de agentes exteriores. (SCHWARTZ, 2019).

O que me motiva assim...é a esperança, a expectativa né!? É a fé de um dia futuramente...eu sei que aos olhos do ser humano, aos olhos do médico não tem cura né!? Mas assim eu dou o máximo, o que eu posso fazer eu dou o máximo de mim pra que futuramente ele possa socializar com as pessoas.” (Mãe Esperança).

"Pra mim é... não tem presente melhor do que você ver eles bem, porque eles estando bem, eu estou bem. (Mãe Gratidão).

[...] e assim das minhas conquistas com eles simples coisas, eles foram pra feira hoje comigo, fizeram a feira comigo no mercado hoje, coisa que nunca tinha acontecido, pra os outros pode ser bobagem, pode ser besteira, mas pra mim não é muito gratificante. (Mãe Gratidão).

O que me motiva é o amor, o amor de mãe, na verdade ele é o meu combustível, tem hora que dá vontade de desistir sim, é difícil a caminhada, tem momentos que, principalmente quando ele entra em crise ou que você não consegue se comunicar, ou que você não consegue driblar uma frustação, que você cede, então você quer desistir, mas ai você olha e diz "Mas ele depende de mim", ai você repensa e volta atrás e é meu tudo é meu amor, o meu filho é o meu combustível da minha vida, tudo é por ele, independente dele ser autista, se ele não fosse autista o sentimento seria o mesmo, ele seria sempre o combustível pra me dar força pra levantar da cama as vezes eu tô cansada, estressada, com dor de cabeça mas é por ele, que tem que ir pra escola, que tem que aprender, que vamos ter que ir pro Mens Sana não pode faltar, então assim é tudo por ele, é sacrifício todos os dias. (Mãe Aprendizado).

Zanello (2018) afirma que existem muitas maneiras diferentes de ser mãe, muitas mulheres conseguem tirar proveito e prazer na maternidade, mas muitas se sentem 
incapazes e frustradas, ser mãe carrega inúmeras responsabilidades, e como o peso da educação e cuidado recai na maioria das vezes sobre ela, as motivações que levam ao cuidado integral estão ligadas as conquistas dos filhos, portanto as motivações são das mais diversas ordens, como ver o filho bem, ouvir palavras de carinho ou até mesmo ao projetar um futuro onde o filho não precise lidar com as dificuldades de possuir uma deficiência.

Para Valas (200I), a mãe inconscientemente coloca aquele filho como objeto de seu desejo, e a demanda do outro torna-se objeto de sua fantasia, ou seja, a fantasia funciona como pulsão, então a mãe passa a ter o filho como objeto de satisfação, de forma que as necessidades do filho passam a ser dela também, da mesma forma que as satisfações e realizações.

Diante das experiências da maternidade é notório o crescimento da sensibilidade da relação mãe-bebê, a qual é capaz de abdicar dos interesses habituais a fim de estruturar uma unidade independente e autossuficiente com o bebê, tendo como objetivo principal suprir os cuidados básicos com o filho. (BONATTI, 2019)

\section{CONSIDERAÇÕES FINAIS}

Os temas aqui abordados explanam a realidade de uma boa parcela de mães brasileiras, as mães que possuem filhos com deficiência e passam por vivências complexas e pouco debatidas nas literaturas da Psicologia e na sociedade em geral. Para entender a realidade do cotidiano do cuidado de filhos com deficiência é preciso entender as subjetividades das mães, as realidades em que vivem. As mulheres da pesquisa vão desde mães que tem ensino superior na área da saúde a mães que não sabem sequer citar a deficiência que o filho possui, a realidade das mulheres diferencia a forma como entendem e lidam com a deficiência de seus filhos.

Diante dos discursos apresentados é possível concluir que as mães adotam o termo da normalidade como padrão, por considerar que algo desviante do normal não se enquadre nos parâmetros que ela considera comuns e aceitáveis. Aderem a fala de que tratam o filho como "normal" em uma tentativa de amenizar a condição dos mesmos. 
As vivências emocionais das mães que possuem filhos com deficiência trazem peculiaridades em suas manifestações, em seu cotidiano as mães deparam-se com novas realidades pouco debatidas, sendo a mãe na maioria das vezes responsável pelo cuidado integral, fator de herança histórica dos modelos de sociedade que estruturam a nossa atualidade, a mãe se coloca como autora das responsabilidades, e tamanho comprometimento sem precedente de escolha, traz para ela sentimentos de culpa por não dar conta de tudo sozinha ou até mesmo de acreditarem que deixam de ser mães por não estar presentes em todos os momentos da vida do filho. Essa construção social liga diretamente o sentimento de ser mãe apenas quando se toma o cuidado integral inteiramente para si e debruça todas as suas vivências em torno do filho.

O estereótipo social do que é ser uma boa mãe não permite que as mães sintam-se tristes ou arrependidas de alguma forma, o dispositivo materno traz consigo uma imagem de alguém que está totalmente debruçada para sobre a vida do filho, alguém livre de defeitos, que mesmo com as dificuldades e angústias não se permite dizer que não estão satisfeitas com a realidade em que vivem, pois isso seria o equivalente a não ter amor suficiente pelo filho.

A maternidade traz consigo uma realidade cercada de dores e prazeres, tais prazeres servem como motivação para a continuação do cuidado constante e integral, pois mesmo que não esteja presente fisicamente, a mãe está presente simbolicamente, pois mesmo distante do filho está sempre pensando e comandando seus cuidados.

Ao se tornar mãe de um filho com deficiência a mulher se anula em parte, deixando de lado alguns prazeres antigos em função dos cuidados extensos para com o filho, dessa forma a satisfação do filho passa a assumir papel nos desejos e realizações dessa mãe, mãe que se anula em dedicação ao filho que necessita de cuidados.

Percebeu-se diante da pesquisa, que é necessário um novo olhar para essas mães, um olhar para a mãe que sofre, mas que também se sente agraciada pela deficiência do filho, da mãe que adequou o seu modo de vida para fazer o melhor pelo filho. A partir de uma compreensão de uma maternidade como algo particular, com significantes singulares e uma experiência de doação e cuidado, dores e amores, espera-se que tanto as mães, como 
as pessoas em geral passem a entender que as fragilidades, o cansaço e a culpa também fazem parte do processo e isso não minimiza o amor entre mãe e filho.

\section{REFERÊNCIAS}

ALVES, E. G. dos R. A morte do filho idealizado. O Mundo da Saúde. São Paulo, v.36, n.I, p.90-97, 2012.

BARDIN, L. Análise de conteúdo. Lisboa: Edições 70, 1977.

BIROLI, F. Gênero e Desigualdades: limites da democracia no Brasil. ı. ed. São Paulo: Boitempo, 2017.

BONATTI, M. C. Contribuições para a compreensão do sofrimento materno na relação mãe-bebê: a mãe com depressão. 2019. $40 \mathrm{f}$. Trabalho de Conclusão de Curso (Graduação em Psicologia) - Universidade Federal de Uberlândia, Uberlândia, 2019.

BRASIL. FGV SOCIAL: Centro de politicas sociais. Qual a faixa de renda familiar das classes, 2014 .

CÂMARA, C. C. R.. Maternidade e Espiritualidade: aspectos simbólicos. Paralellus revista eletrônica em ciência da religião. Recife, v. 6, n. 13, p. 467-494, 2015.

DONATH, O. Mães arrependidas: uma outra visão da maternidade. Tradução Marina Vargas. I. ed. Rio de Janeiro: Civilização Brasileira, 2016. 252 p.

HUERTAS, J. A. Motivación: Querer aprender. Buenos Aires: Aique, 200I.

LEBOVICI, S. A mãe, o bebê e o psicanalista. Porto Alegre: Artes Médicas, 1987.

MALTA, D. C. et al. Prevalência autorreferida de deficiência no Brasil, segundo a Pesquisa Nacional de Saúde, 2013. Rio de Janeiro, Ciência \& Saúde Coletiva, v. 2I, 2016.

MARCONI, M. de A.; LAKATOS, E. M.. Fundamentos de metodologia científica. 5. ed. São Paulo: Editora Atlas, 2003.

MARTINS, C. A. et al. Tornar-se pai e mãe: um papel socialmente construído. Revista de Enfermagem Referência. Coimbra, v.4, n.2, 2014.

MINAYO, M. C. de S. O desafio do conhecimento. Pesquisa qualitativa em saúde. $9^{\underline{a}}$ edição revista e aprimorada. São Paulo: Hucitec, 2006.

NOGUEIRA, G. C. et al. Perfil das pessoas com deficiência física e Políticas Públicas: a distância entre intenções e gestos. Ciência \& Saúde Coletiva. Florianópolis, v. 2I, 2016. 
OLIVEIRA, I. G. de; POLETTO, M. Vivências emocionais de mães e de pais de filhos com deficiência. Revista da Sociedade de Psicoterapias Analíticas Grupais do Estado de São Paulo, v. I6, n. 2, p.I02-I19, 2015.

OLIVEIRA, M. C. P. et al. Contribuições da avaliação mediada para a escolarização de alunos com deficiência intelectual. Revista Teias. Rio de Janeiro, v. I7, n. 46, 2016.

REY, L. Dicionário de termos técnicos de medicina e saúde. $2^{\circ}$ edição. Rio de Janeiro: Editora Guanabara Koogan, 2003.

SCAVONE, L. Dar a vida e cuidar da vida: feminismo e ciências sociais. São Paulo: Editora UNESP, 2004 .

SCHWARTZ, S. Motivação para ensinar e aprender: teoria e prática. Rio de Janeiro: Vozes, 2019.

SILVA, C. M. da; MACEDO, M. M. K. O método psicanalítico de pesquisa e a potencialidade dos fatos clínicos. Psicologia: Ciência e Profissão, v. 36, n. 3, p. 520-533, 2016.

SMEHA, L. N.; CEZAR, P. K. A vivência da maternidade de mães de crianças com autismo. Psicologia em Estudo, Maringá, v. I6, n. I, p. 43-50, 201 I.

TOMAZ, R. V. V. et al. Impacto da deficiência intelectual moderada na dinâmica e na qualidade de vida familiar: um estudo clínico-qualitativo. Cadernos de Saúde Pública. São Carlos, 2017.

VALAS, P. As dimensões do gozo: do mito da pulsão a deriva do gozo. Rio de Janeiro: Jorge Zahar Ed., 20or.

ZANELLO, V. Saúde mental, gênero e dispositivos: Cultura e processos de subjetivação. I. Ed. Curitiba: Appris, 2018. 30I p. 